\title{
GIS and AHP Based Site Suitability for Sewage Treatment Plant in Sultanpur District, India
}

\author{
Ruchin Agrawal, Amitabh Kumar Srivastava, Anjani Kumar Nigam
}

\begin{abstract}
Sewage generated from the urban areas is creating an unwanted burden on the environment. This makes it necessary for the urban areas to have the facility of sewage treatment plant. But where? As the STP have with them associated environmental and other risks, high cost of land and other factors making this decision a tricky one. It is at this juncture where technology in the form of GIS and AHP comes in picture to rescue the planners and decision-makers. In the present study it is shown how the GIS and AHP methods can be used to shortlist and rank the various site to be used to house a sewage treatment plant. STP site (S5) was found to be top-ranked among all other sites.
\end{abstract}

Index Terms: AHP, GIS, Ranking, Site Selection, STP.

\section{INTRODUCTION}

Effluents generated from the domestic activities in the urban areas pose a serious challenge to the environment, thus appropriate treatment is a must before discharging them (CEC 1991, Metcalf \& Eddy 2003). With the increase in urbanization this problem of sewage has also turned in to a nightmare for the planners and decision-makers. Thus, installing sewage treatment plants a trivial solution to the problem in plain sight.

However, discharge from the sewage treatment plant also pose a threat to the ecosystem (Smith et al. 1999, Hughes 2004), making it very crucial for the planners and decisionmakers to take suitable decision on the location for the sewage treatment plant (Fraschetti et al. 2006, Milnes and Perrochet 2007) so that its footprint on the ecosystem can be minimized.

GIS-based spatial analysis for site suitability evaluation (Zhao et al. 2009) followed by multi-criteria analysis for optimal evaluation of alternatives form a very powerful tool that supports complex decision-making process (Anagnostopoulos et al. 2007). Sewage treatment plant site suitability analysis is one such problem that can have the leverage of these tools to achieve a great result for the stake holders.

\section{METHODOLOGY}

\section{Spatial Analysis}

Geographic Information System (GIS) for quite some time has become a robust tool (Burrough and McDonnell 1998) for planners and decision-makers to gather, store,

Revised Manuscript Received on April 12, 2019.

Ruchin Agrawal, Assistant Professor, Civil Engineering Department Kamla Nehru Institute of Technology, Sultanpur, India.

Amitabh Kumar Srivastava, Professor, Civil Engineering Department Bundelkhand Institute of Engineering and Technology, Jhansi, India.

Anjani Kumar Nigam, Professor, Civil Engineering Department Bundelkhand Institute of Engineering and Technology, Jhansi, India. analyze spatial and attribute data (Martínez-Graña et al 2014, Li et al. 2016); and thereafter arrive at solution through analysis of some very complex problems which otherwise would have been posing a serious challenge to deal with (Aguilera et al. 2011, He et al. 2011, Xie et al 2012). GIS can be put to use in a multitude of applications. Site suitability analysis for various land uses is one such application, where GIS can be very useful (Brail and Klosterman, 2001; Collins et al., 2001).

Therefore, GIS has been successfully used here in the site suitability analysis for Sewage Treatment Plant. This analysis provides a number of alternatives to choose from, for siting sewage treatment plant, based on some welldefined spatial criteria.

\section{Multi-Criteria Analysis}

Alternatives obtained after GIS analysis can then be ranked by Multi-Criteria Analysis. These ranks will then help the planners and decision-makers to choose the best alternative for siting the sewage treatment plant. MultiCriteria Analysis is carried out by the Analytical Hierarchy Process (AHP) (Saaty 2013).

In AHP, hierarchy of complex problem is established with goals (objectives) at the top of hierarchy, criterions at levels, sub-criterions at sub-levels and decision alternatives at the bottom of the hierarchy. Pairwise comparison of elements at each hierarchy level is then carried out. The method thus computes and aggregates their eigenvectors until the composite final vector of weight coefficients for alternatives is obtained. The entries of final weight coefficients vector reflect the relative importance (value) of each alternative with respect to the goals stated at the top of the hierarchy. The alternative with the highest weight coefficient value should be taken as the best alternative.

\section{CASE STUDY}

Study Area

An area if $112.81 \mathrm{~km} 2$ and geographical extent of $26019^{\prime}$ $42.918^{\prime \prime} \mathrm{N}$ to $26025^{\prime} 20.42$ " N latitude and $81058^{\prime}$ '30.897" E to 820 5' 4.079" E longitude in Sultanpur district of U.P., India has been chosen for the present study. River Gomti flows through the center of the study area, which mainly comprises of quaternary alluvium.

The area has rural to semi-urban populace, which is in a state of urbanization at a fast pace. Kurwar town being at the 
center of this transition (from rural to urban) is attracting the attention of planners. Thus, making this area a very suitable candidate to be considered for the present study.



Fig. 1: Study Area

\section{Spatial Data}

Spatial data in the form of GIS maps were created to be utilized in the present study. Following is the list of maps:-
1. Land Use Map
2. Soil Map
3. Slope Map
4. Transportation Map
5. Drainage Map
6. Flood Map
7. Geological Map

\section{GIS Analysis}

Criteria for spatial analysis for suitability of siting sewage treatment plant has been decided upon by a group of 14 experts (team of academicians, people of municipal authorities, and researchers) after due brain-storming and discussions based upon detailed study of the literature available in public domain. Finalized criteria for analysis is as follows:-

1. Distance from Settlement: Sewage treatment plant should be located at least $500 \mathrm{~m}$ away from the habituated area.

2. Distance from Road: Sewage treatment plant should be constructed within $200 \mathrm{~m}$ from road, so that it can have an easy access.

3. Distance from Pond: Sewage treatment plant should be located at least $200 \mathrm{~m}$ away from pond, so as to avoid contamination of surface water.

4. Distance from landfill: Sewage treatment plant should be located at least $300 \mathrm{~m}$ away from landfill, so as to avoid compounding of contamination issue.

5. Slope: Site with slight slope is preferable to facilitate gravity flow of wastewater through treatment units.

Based on the criteria laid down as above a GIS model was developed, which was then used to carry out the spatial analysis for finding out the suitable site location for the sewage treatment plant.

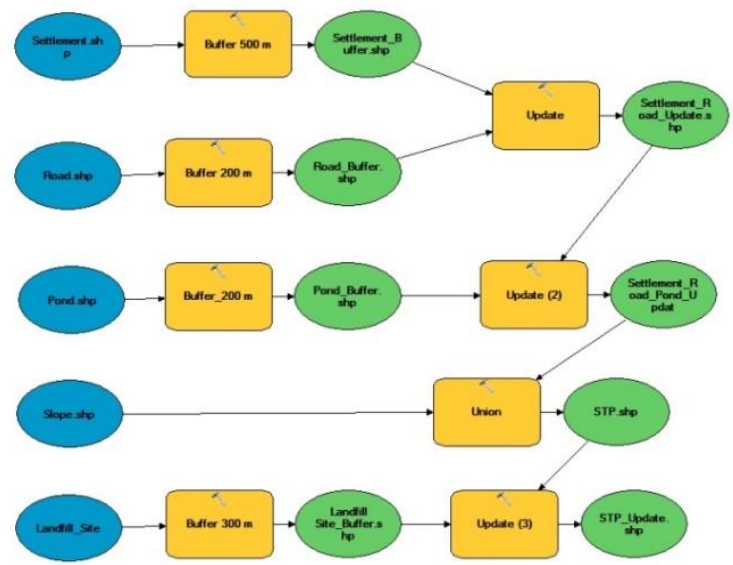

Fig. 2: GIS Model for STP Site Selection

After applying the GIS model (Fig, 2) to the spatial data, the result obtained was a map (Fig. 3) with six suitable proposed candidate sites that can be used for construction of Sewage Treatment Plant. The locational details (geographic coordinates) of these sites are given in Table 1. For the ease of denotation, these sites are christened as S1 to S6. The detailed values of the various spatial criteria for the candidate sites are given in Table 2.

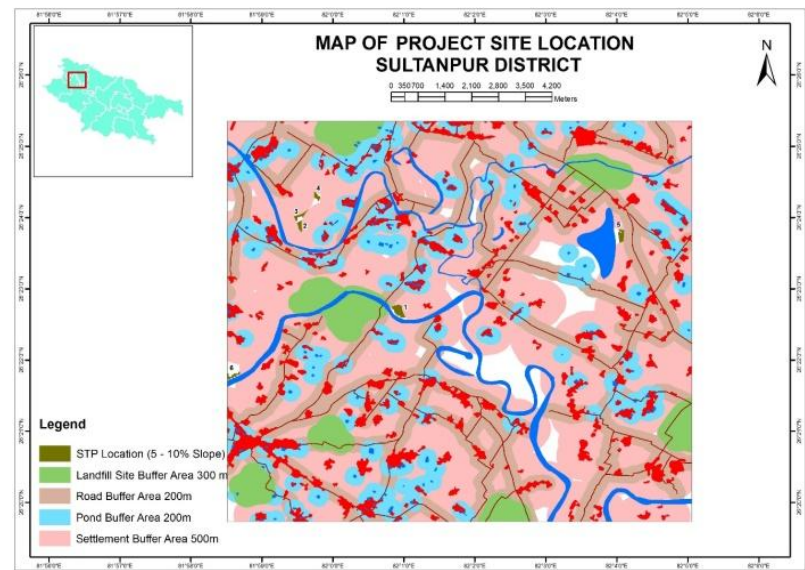

Fig. 3 Map showing proposed location for STP

Table 1: Geographic coordinates of six candidate site for STP

\begin{tabular}{|l|l|l|}
\hline \multicolumn{1}{|c|}{ STP Site } & \multicolumn{2}{c|}{ Coordinates } \\
\hline \multirow{2}{*}{ Project Site 1 (S1) } & longitude & $82^{\circ} 0^{\prime} 55.478^{\prime \prime} \mathrm{E}$ \\
\cline { 2 - 3 } & latitude & $26^{\circ} 22^{\prime} 41.436^{\prime \prime} \mathrm{N}$ \\
\hline \multirow{2}{*}{ Project Site 2 (S2) } & longitude & $81^{\circ} 59^{\prime} 32.183^{\prime \prime} \mathrm{E}$ \\
\cline { 2 - 3 } & latitude & $26^{\circ} 23^{\prime} 52.914^{\prime \prime} \mathrm{N}$ \\
\hline
\end{tabular}




\begin{tabular}{|l|l|l|}
\hline \multirow{2}{*}{ Project Site 3 (S3) } & longitude & $81^{\circ} 59^{\prime} 32.144^{\prime \prime} \mathrm{E}$ \\
\cline { 2 - 3 } & latitude & $26^{\circ} 24^{\prime} 1.311^{\prime \prime} \mathrm{N}$ \\
\hline \multirow{2}{*}{ Project Site 4 (S4) } & longitude & $81^{\circ} 59^{\prime} 46.450^{\prime \prime} \mathrm{E}$ \\
\cline { 2 - 3 } & latitude & $26^{\circ} 24^{\prime} 17.604^{\prime \prime} \mathrm{N}$ \\
\hline \multirow{2}{*}{ Project Site 5 (S5) } & longitude & $82^{\circ} 4^{\prime} 3.7466^{\prime \prime} \mathrm{E}$ \\
\cline { 2 - 3 } & latitude & $26^{\circ} 23^{\prime} 44.695^{\prime \prime} \mathrm{N}$ \\
\hline \multirow{2}{*}{ Project Site 6 (S6) } & longitude & $81^{\circ} 58^{\prime} 35.281^{\prime \prime} \mathrm{E}$ \\
\cline { 2 - 3 } & latitude & $26^{\circ} 21^{\prime} 46.737^{\prime \prime} \mathrm{N}$ \\
\hline
\end{tabular}

Table 2: Values of various spatial criteria for different STP candidate sites

\begin{tabular}{|c|c|c|c|c|c|c|}
\hline & \multicolumn{7}{|c|}{ Candidate STP Site } \\
\cline { 2 - 7 } & S1 & S2 & S3 & S4 & S5 & S6 \\
\hline Level (C1) & 90.860811 & 89.068882 & 89.357481 & 89.080073 & 89.268392 & 90.881455 \\
\hline Area in ha (C2) & $6.14 \mathrm{ha}$ & $2.09 \mathrm{ha}$ & $2.34 \mathrm{ha}$ & $1.85 \mathrm{ha}$ & $3.62 \mathrm{ha}$ & $2.40 \mathrm{ha}$ \\
\hline Slope (C3) & $5-10 \%$ & $5-10 \%$ & $5-10 \%$ & $5-10 \%$ & $5-10 \%$ & $5-10 \%$ \\
\hline $\begin{array}{c}\text { Distance Nearest } \\
\text { Pond (m) (C4) }\end{array}$ & $609.65 \mathrm{~m}$ & $475.11 \mathrm{~m}$ & $645.14 \mathrm{~m}$ & $659.28 \mathrm{~m}$ & $852.52 \mathrm{~m}$ & $134.78 \mathrm{~m}$ \\
\hline $\begin{array}{c}\text { Distance Nearest } \\
\text { Road (m) (C5) }\end{array}$ & $285.9 \mathrm{~m}$ & $995.12 \mathrm{~m}$ & $804.92 \mathrm{~m}$ & $743.05 \mathrm{~m}$ & $313.74 \mathrm{~m}$ & $200.60 \mathrm{~m}$ \\
\hline $\begin{array}{c}\text { Distance Nearest } \\
\text { River (m) (C6) }\end{array}$ & $129.96 \mathrm{~m}$ & $377.10 \mathrm{~m}$ & $339.86 \mathrm{~m}$ & $845.13 \mathrm{~m}$ & $107.49 \mathrm{~m}$ & $1534.88 \mathrm{~m}$ \\
\hline $\begin{array}{c}\text { Distance Nearest } \\
\text { Settlement (m) (C7) }\end{array}$ & $500.06 \mathrm{~m}$ & $590.40 \mathrm{~m}$ & $507.62 \mathrm{~m}$ & $501.83 \mathrm{~m}$ & $701.78 \mathrm{~m}$ & $500.23 \mathrm{~m}$ \\
\hline
\end{tabular}

\section{AHP Analysis}

AHP analysis was carried out on the seven criterions stated above in the Table 2 to determine the most suitable STP site from amongst the candidate sites. Based on the expert opinion collected from a group of 14 people consisting of academicians, researchers and people from municipal authorities, pair-wise comparison of each criteria was carried out. Thereafter, weightage of each criteria was calculated using the AHP analysis. These weightages were then used to calculate the percentage suitability, which in turn provided the rank of each candidate site as shown in Table 3 below.

Table 3: Percentage suitability of different candidate

STP sites

\begin{tabular}{|c|c|c|}
\hline Candidate Sites & Percentage Suitability & Rankings \\
\hline S5 & 23.38 & 1 \\
\hline S1 & 21.62 & 2 \\
\hline S6 & 17.23 & 3 \\
\hline S3 & 13.29 & 4 \\
\hline S2 & 12.88 & 5 \\
\hline S4 & 11.59 & 6 \\
\hline
\end{tabular}

\section{RESULTS AND DISCUSSIONS}

The candidate sites were then arranged according to their ranks for the creation of Map of STP site suitability ranking as shown in the Fig. 4 below. STP site S5 is the most preferred one as per the GIS-AHP site with percentage suitability of $23.38 \%$. Suitable values of this site (S5) for criterion $\mathrm{C} 2, \mathrm{C} 4, \mathrm{C} 6$, and $\mathrm{C} 7$ made it the most preferred. Whereas on the other hand STP site S4 with percentage suitability of $11.59 \%$ is the least preferred one. Values of this site for criterion C2, C5 and C6 have made this site the least preferred.

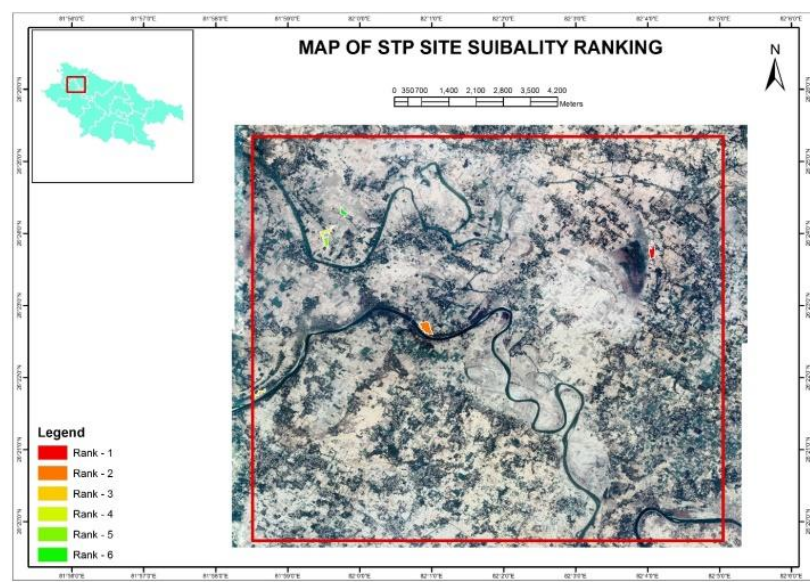

Fig. 4: Final map showing rank-wise STP sites

\section{CONCLUSION}

Site selection for a sewage treatment plant is a very challenging task involving socio-economical, environmental and technical dimension. Political influences and interests of locals also add to the complication. This study has hereby shown that a step-wise solution can be provided to the mentioned problem by breaking it into two parts. First being solved by GIS on the basis of very well defined spatial criteria. Second being prioritizing the already finalized site choices so as to address conflicts and ambiguity in a rational manner.

Therefore, this study justifies the proposition that an integration of GIS and AHP methods can be very fruitful in solving problems having multi-dimensional scope and conflict of interests of stakeholders.

\section{REFERENCES}

1. Anagnostopoulos K P, Gratziou M, Vavatsikos A P. Using the fuzzy Analytic Hierarchy Process for selecting wastewater facilities at prefecture level. European Water 2007; 19/20: 15-24.

2. Brail R K, Klosterman R E. Planning Support Systems, ESRI Press, Redlands, CA, 2001.

3. Burrough, P A, McDonnell RA. Principles of Geographical Information Systems, Oxford University Press, Oxford, 1998.

4. CEC, 1991. Council Directive 91/271/EEC concerning urban wastewater treatment. Official Journal of the European Community, L135/40.

5. Collins M G, Steiner F R, Rushman M J. Land-use suitability analysis in the United States: historical development and promising technological achievements. Environmental Management, 2001; 28 (5):611-621.

6. Fraschetti S, Gambi C, Giangrande A, Musco L, Terlizzi A, Danovaro R. Structural and functional response of meiofauna rocky assemblages to sewage pollution. Marine Pollut Bull 2006; 52(5):540-8.

7. Hughes KA. Reducing sewage pollution in the Antarctic marine environment using a sewage treatment plant. Marine Pollut Bull 2004; 49(9-10):850-3.

8. Li X, Hijazi I, Koening R, Lv Z, Zhong C, Schmitt G. Assessing Essential Qualities of Urban Space with Emotional and Visual Data Based on GIS Technique. ISPRS Int. J. Geo Inf. 2016; 5:218.

9. Martínez-Graña A M, Goy J L, Zazo C. Water and wind erosion risk in natural parks. A case study in "Las BatuecasSierra de Francia" and "Quilamas" protected parks (Central System, Spain). Int. J. Environ. Res. 2014;, 8:61-68. 
10. Metcalf \& Eddy, 2003. Wastewater Engineering-Treatment, Disposal, Reuse. 4th Edition. New York: McGraw-Hill.

11. Milnes E, Perrochet P. Simultaneous identification of a single pollution point-source location and contamination time under known flow field conditions. Adv Water Resour 2007; 30(12):2439-46.

12. Saaty T L. The Modern Science of Multicriteria Decision Making and Its Practical Applications: The AHP/ANP Approach. Oper. Res., 2013; 61:1101-1118.

13. Smith AK, Ajani PA, Roberts DE. Spatial and temporal variation in fish assemblages exposed to sewage and implications for management. Marine Environ Res 1999; 47(3):241-60.

14. Xie Z, Liu J, Ma Z, Duan X, Cui Y. Effect of surrounding land-use change on the wetland landscape pattern of a natural protected area in Tianjin, China. Int. J. Sustain. Dev. World Ecol. 2012; 19:16-24.

15. Zhao YW, Qin Y, Chen B, Zhao X, Li Y, Yin X A, Chen G Q. GIS-based optimization for the locations of sewage treatment plants and sewage outfalls - A case study of Nansha District in Guangzhou City, China. Communications in Nonlinear Science and Numerical Simulation 2009; 14:17461757.

\section{AUTHORS PROFILE}

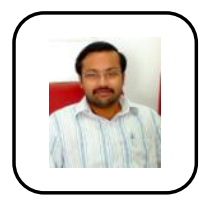

Ruchin Agrawal is B.E. (Civil Engineering) and M.Tech. (Remote Sensing \& GIS) and currently pursuing Ph.D. with 3 years of industrial experience and almost 10 years of teaching experience. Author has around 10 publications in national, international journals and conferences. Author is a life member of ISG, ISRS and has been diligently contributing to the field of Remote Sensing and GIS. Also with interest in transportation engineering, author has been earnestly working in this field as well.

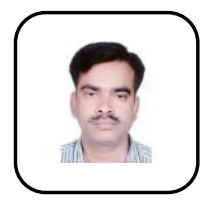

Amitabh Kumar Srivastava was born in Gorakhpur, India, in 1971. He received the B.E. degree in civil engineering from the Regional Institute of Technology Jamshedpur, India, in 1993, and the M.Tech. and Ph.D. degrees in environmental engineering from the MNREC Allahabad and Indian Institute of Technology (IIT) Delhi, New Delhi, India, in 1997 and 2008, respectively.

In 1999, he joined the Department of Civil Engineering, Bundelkhand Institute of Engineering \& Technology Jhansi, as a Lecturer, and in 2009 became a Reader. Since April 2015, he was promoted as Professor. His current research interests include waste management, risk analysis and system modeling.

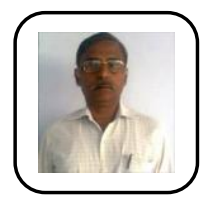

Dr. Anjani Kumar Nigam is currently Professor and Head in Civil Engineering Department, BIET Jhansi. With 30+ years of teaching and research experience he has been working in the specialized field of Remote Sensing and GIS and also in Structural Engineering. $\mathrm{He}$ has 30+ publications in various National and International Journals and conferences of repute. 